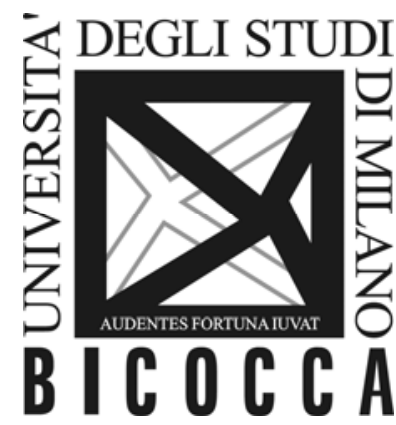

DEPARTMENT OF ECONOMICS

UNIVERSITY OF MILAN - BICOCCA

WORKING PAPER SERIES

Attracted but Unsatisfied: The Effects of Arousing Contents on Television Consumption Choices

Luca Stanca, Marco Gui, and Marcello Gallucci No. 203 - February 2011

Dipartimento di Economia Politica

Università degli Studi di Milano - Bicocca

http://dipeco.economia.unimib.it 


\title{
Attracted but Unsatisfied: The Effects of Arousing Content on Television Consumption Choices*
}

\author{
Luca Stanca ${ }^{\dagger}$ Marco Gui, ${ }^{\ddagger}$ and Marcello Gallucci ${ }^{\S}$ \\ University of Milano Bicocca
}

February 2011

\begin{abstract}
This paper investigates experimentally the effects of arousing content on viewing choices and satisfaction in television consumption. We test the hypothesis that the portrayal of arousing content combines high attraction and low satisfaction and is thus responsible for suboptimal choices. In our experiment, subjects can choose among three programs during a viewing session. In the experimental condition, one of the three programs portrays a violent verbal conflict, whereas in the control condition the same program portrays a calm debate. A post-experimental questionnaire is used to assess subjects' satisfaction with the programs and the overall viewing experience. The results support the hypothesis: the presence of arousing content causes subjects to watch more of a given program, although they experience lower content-specific and overall satisfaction. Arousing contents also significantly increase the discrepancy between actual and desired viewing.
\end{abstract}

JEL: D63, C78, C91

Keywords: Rational Choice, Audience, Television, Satisfaction, Arousing content, Laboratory Experiments.

*We thank the Osservatorio di Pavia - Media Research and Telecom Italia, for providing us with audiovisual content used for the experiment. We acknowledge financial support from CISEPS, University of Milano Bicocca.

${ }^{\dagger}$ Corresponding author. Department of Economics, University of Milan Bicocca, Piazza dell'Ateneo Nuovo 1 (U6-367), 20126 Milan, Italy. E-mail: luca.stanca@unimib.it

‡Department of Sociology, University of Milan Bicocca, Piazza dell’Ateneo Nuovo 1, 20126 Milan, Italy. E-mail: marco.gui@unimib.it

${ }^{\S}$ Department of Psychology, University of Milan Bicocca, Piazza dell'Ateneo Nuovo 1, 20126 Milan, Italy. E-mail: marcello.gallucci@unimib.it 


\section{Introduction}

It is widely acknowledged that specific kinds of contents are overrepresented in the media, relative to their presence in real life, with the aim of catching viewers' attention (McQuail, 2005, 359). Concerns about the overwhelming use of arousing contents in television programs have been expressed by sociologists like Pierre Bourdieu (1998) and philosophers like Karl Popper (1993), who condemn the use of sensation seeking contents to attract television audience. In journalism studies, the concept of "newsworthiness" is traditionally used to define those features which explain the emergence of news stories, such as novelty, titillation, dramatization, and personalization (see for example Chibnall, 1977, Meyers, 1997). Voyeurism, for example, has been identified as an important factor in explaining the appeal of reality TV shows (Baruh, 2009).

More recently, the concept of sensationalism has been analyzed empirically with respect to both the content and the formal characteristics of television programs (Grabe et al., 2001; Grabe et al., 2003). The sensationalistic features of television news have increased substantially in the last decades (Slattery et al., 2001; Hendrik Vettehen et al., 2005; Hardy et al., 2010). The effects of sensational contents on viewers have been explained using the psychological mechanism of emotional arousal (Hendrik Vettehen, 2008). Arousing content has been defined as content that elicits emotion in viewers, as measured by a broad range of physiological indicators (Lacey and Lacey, 1974; Lang, 1990; Lang, 1994; Lang et al., 1999; Lang, et al., 1996; Simons et al., 2003). Uribe and Gunter (2007), reviewing the literature on the relationship between sensational news stories and emotional arousal, identify six content categories that can be linked to emotional arousal: sex, violence, destruction, humour, celebrities and other emotional content (a further generic category principally referred to the audio or visual portrayal of people expressing emotions such as sadness, anger, hunger or happiness). Violence, in particular, has been found to generate neural arousal in viewers (Newhagen, 1998; Grimm, 1996).

In the last fifteen years, experimental psychology has demonstrated that arousing contents increase automatic attention and resource allocation to the processing of television messages (Lang et al., 1995; Lang et al., 1999; Newhagen and Reeves, 1992; Grabe et al., 2003). Other effects of arousing contents have been studied with respect to the availability of cognitive resources (Lang et al., 2007), memory (Bolls et al., 1996), self-selection of viewers (Kremar and Greene, 1999), and aggressive behavior (Anderson and Bushman, 2001). However, to the best of our knowledge, there is no experimental evidence on how arousing content affects the relationship between viewing choice and 
satisfaction with viewing. The complexity of this relationship has not been taken into consideration in this field of research. Satisfaction ("liking") has been used as a proxy for consumption ("exposure") when examining the effect of different levels of arousal in the news (Hendrik Vettehen et al., 2008).

In other fields, the relationship between actual choices and ex-post satisfaction is attracting a growing interest. Systematic inconsistencies between behavior and perceived satisfaction have been found to occur in many domains of consumption (e.g. Gruber and Mullainathan, 2002, Cutler et al., 2003, Shapiro, 2005). As far as TV consumption is concerned, Frey at al. (2007) and Bruni and Stanca (2006, 2008), among others, have studied empirically the relationship between television viewing and life satisfaction, finding relevant contradictions. However, in this field of research the role of specific kinds of TV content has not been taken into consideration, nor has it been studied experimentally.

The effect of arousing contents on the relationship between consumption and satisfaction represents a relevant issue for two main reasons. First, if arousing contents cause automatic attentive reactions, attention can be directed irrespective of, or even in contrast with, viewers' will and interest. This can be all the more true as the possibilities of instinctive choices during television viewing have been highly enhanced by the introduction of the remote control (Perse and Ferguson, 1993; Walker and Bellamy, 1993). Second, we know that audience figures are used in the commercial media market almost as the only measure to assess TV programs' performance, as if the quantity of viewers could be used as a proxy for appreciation. It is therefore important to understand if and how arousing contents can bias this relationship by producing an inconsistency between the type of content chosen by viewers and their satisfaction. This phenomenon would imply that a widespread use of arousing contents in television programs would result in sub-optimal viewing choices.

In this paper, we test experimentally the hypothesis that arousing contents combine a high potential for attraction and low levels of ex-post satisfaction and can therefore be responsible for sub-optimal behavior in television consumption. Among the different kinds of arousing contents, we focus on the portrayal of verbal violence, one of the most common forms of violence on television (Potter, 1996), that is particularly widespread in talk shows (Wood, 2001). ${ }^{1}$ In our experiment, subjects can freely choose among three programs during a viewing session with a given time span. In the experimental treatment, one of the three programs portrays a violent verbal conflict,

\footnotetext{
${ }^{1}$ Violence in the media has always attracted particular interest in both researchers and public opinion for its links with real-life aggressive behaviors (see Johnson et al., 2002; see Potter, 1996 for a review of previous studies).
} 
whereas in the control treatment the same talk show does not contain arousing contents. A post-experimental questionnaire is used to assess subjects' satisfaction about the programs and the overall viewing experience. The results strongly support the hypothesis. On the one hand, the presence of arousing content causes subjects to watch more of a given program. On the other hand, subjects experience lower content-specific and overall satisfaction. These findings are robust to the use of different program types (lowbrow vs highbrow) for the manipulation of arousingness. The analysis of the post-experimental questionnaire indicates that subjects clearly perceive their own viewing choices. They are also aware of several negative features of arousing contents. However, in the presence of arousing contents, the viewing experience is perceived as more entertaining.

The remainder of the paper is organized as follows. Section 2 briefly reviews the related literature. Section 3 describes the experimental design and procedures. Section 4 presents the results. Section 5 concludes.

\section{Related Literature}

International research on the use of media has often identified inconsistencies between viewers' exposure to specific programs and their ex-post satisfaction. For certain television programs, audience size and appreciation measures are not necessarily related (Gunter and Wober, 1992). The same applies when comparing audience figures with perceived quality measures: viewers often report to watch programs they find of poor quality (Morrison, 1986; Wober, 1990). Measures of perceived quality, in turn, also differ from self-reported appreciation (Gunter and Wober, 1992; Leggatt,1996; Ishikawa, 1996; Weimann et al., 1992). Overall, this evidence indicates that in television consumption, figures on viewing, appreciation and perceived quality can be largely unrelated (see Gui and Stanca, 2009, for a review). Evidence supporting this contradictory behavior comes from recent qualitative research on young viewers, who seem to select their exposure to TV irrespective of both the significance attributed to content and its perceived quality and reliability (Meijer, 2007; Lundy et al., 2008). These studies explain this finding with reference to the perceived escapism and social affiliation needs (Lundy et al., 2008) or to the prevalence of entertainment on the quality of the program content (Meijer, 2007). Other traditional explanations of such inconsistencies point to social desirability biases. Ang (1985), for example, argues that people tend to criticize television programs and to share their feelings with others because this provides them with a social bond. Therefore, it is difficult to assess whether people are sincere when they express low appreciation or perceived quality for programs that have high audience figures. This is an 
important point, as appreciation for niche and cultural contents is generally higher than appreciation for entertainment and programs for mass targets (see, for example, Heuvelman et al., 2005, 333). McQuail (1997) proposes a further possible explanation: quality measures can easily vary, independently of ratings, because television programs intended for a minority taste can be viewed by a large audience that has inappropriate expectations and therefore will be particularly disappointed.

All these explanations are based on the framework of a "rational audience": they assume that "people watch what they like on television and like what they watch" (McQuail, 1997, p. 58). In this perspective, viewers would always be able to choose for their best, so that the inconsistencies between viewing choices and appreciation would derive either from difficulties in measuring appreciation, or from practical limitations in viewing. In recent years, however, the existence of relevant contradictions between consumption choices and preferences has received increasing attention in the social sciences. Several instances of time-inconsistent preferences and self-control problems have been emphasized in many fields of human behavior. It has been argued that consumers frequently "act against their own better judgment, engaging in behavior that is often regretted after the fact and that would have been rejected with adequate forethought" (Hoch and Loewenstein, 1991). Gruber and Mullainathan (2002), for example, have shown how cigarette consumers are prone to overconsumption to the point that, when they are not under the need of smoking, a relevant number say they would vote in favor of raising taxes on tobacco. Cutler et al. (2003) and Shapiro (2005) describe similar phenomena in food consumption. From these studies it emerges that there are fields of consumption in which subjects are systematically not satisfied with their choices, but nonetheless they keep making them. Behavioral economics started to distinguish between "choice utility", as revealed by choices, which are prone to mistakes in maximizing utility, and "true utility" as revealed by hedonic measures, such as self-reported happiness or life satisfaction (Gul and Pesendorfer, 2005; Samuelson and Swinkel, 2006).

For TV consumption, in particular, it has been argued that viewers often watch more TV than they would like to. In a field study, subjects reported feeling relaxed and passive both before and during TV watching, but that the sense of relaxation ended quickly when they stopped watching TV (Kubey and Csikszentmihalyi, 1990). The authors argue that one has to keep watching in order to keep feeling relaxed, and this can be at the basis of television overconsumption. Frey et al. (2007) show that high levels of television consumption are negatively related with individual life satisfaction and that this is not consistent with a reverse causality interpretation. Benesch et al. 
(2006) demonstrate how having a larger choice set of TV channels does not raise people's subjective well-being. Instead, when exposed to more channels, heavy viewers report lower life satisfaction. These results, however, lack a distinction between different kinds of contents. The relevant question therefore is: are the inconsistency effects independent of the kind of television content portrayed or is there a relationship between inconsistencies and specific content characteristics?

As it has been demonstrated that arousing contents produce automatic attention in television viewers (Lang et al., 1999; Lang et al., 1995; Newhagen and Reeves, 1992; Grabe et al., 2003), we believe that inconsistencies in viewing can be better explained by analyzing the role of these content features. Indeed, the overconsumption and inconsistencies described above could have a root in attentive mechanisms that act faster or irrespective of viewers' rational exposure choices. Arousing contents can also be linked to dissatisfaction because they leave viewers with negative feelings. Recently, Weaver and Wilson (2009) have shown experimentally that the insertion of television violence within a specific audiovisual product diminishes reported ex-post enjoyment for viewing. In another experimental analysis, however, Hendrik Vettehen et al. (2008) find that the level of content arousal has an inverted U-shape effect on viewers liking of news: both low and high levels of emotional arousal are associated with low levels of liking. The authors assume that liking is predictive of behavior and suggest that not only low but also high levels of emotional arousal may induce news viewers to switch channel. However, there is a lack of experimental evidence on this assumption. We need to know how the relationship between exposure choices and satisfaction changes in the presence or in the absence of arousing content.

\section{The Experiment}

The experiment is designed to test the hypothesis that arousing contents combine a high potential for attraction and low levels of ex-post satisfaction. Under this hypothesis, arousing contents can be responsible for systematic sub-optimal choices of television programs, reflected in higher viewing shares in the absence of higher satisfaction. In the experiment, we focus on contents characterized by verbal violence. Among different kinds of arousing contents, violence has always attracted particular interest from both researchers and public opinion. Research based on content analysis demonstrates that the amount of violence depicted on TV is far greater than what occurs in reality (Gerbner et al. 1979, 1980; Shanahan and Morgan, 1999). At the same time, experimental research has demonstrated a link between viewing televised violence and real-life aggressive behaviors (Johnson et al., 2002; see Potter, 
1996, for a review of previous studies). ${ }^{2}$ According to Potter (1996) the most common form of violence on television consists of aggressive verbal acts, accounting for 64.3 per cent of all aggressive acts. This form of violence is particularly common in talk shows, where conflict is often devised by authors and showmen in order to attract and retain the audience attention (Wood, 2001).

\subsection{Design}

The experimental task consists of watching television for a 10 minute time span, having the opportunity to choose among three programs: a serial, a talk show, and a documentary (A, B, C, respectively). Choices are made in real time, so that subjects can switch at any time among the three programs.

The experiment is based on a 2x2 design, implemented between subjects. The main experimental factor is the arousing level of program $B$ contents. In the experimental condition $(\mathrm{AC})$, program $\mathrm{B}$ portrays arousing contents: during the talk show there is a violent verbal confrontation among the participants. In the control condition (CC), program B is the same as in the experimental condition, but without the arousing content. More specifically, in the control condition program B is an excerpt from the same talk show and episode as in the experimental condition, but it refers to an earlier part, when a calm conversation takes place among the participants. The second experimental factor is aimed at assessing the robustness of the results to the use of different program topics and, in particular, the type of audience they target. Accordingly, the topic of the talk show for program B is varied orthogonally to the main experimental factor. In one experimental condition program B is a relatively lowbrow talk show (Low, sessions 1 to 4), focusing on real-life stories, gossip and current affairs. In the particular episode used in the experiment, guests discuss stalking episodes. In the other experimental condition, program B is a relatively highbrow talk show (High, sessions 5 to 8), where guests discuss current political issues. ${ }^{3}$

Programs A and C, used as benchmarks, are kept constant across treatments. They were chosen as a benchmark since they represent different genres but do not portray emotionally arousing contents such as sex, violence, or conflict. More specifically, program A is a TV serial set in the 18th century. Program $\mathrm{C}$ is a documentary about the social integration of a young

\footnotetext{
${ }^{2}$ Violence has been found to generate a neural arousal in viewers (Newhagen, 1998; Grimm, 1996) and to be the strongest emotion-provoking content on TV news for children (van der Molen et al., 2002).

${ }^{3}$ Viewing figures indicate that the lowbrow talk show presents an audience profile with a large percentage of low educated viewers. The highbrow talk show obtains a high share among viewers with tertiary education.
} 
Moroccan immigrant in Italy. ${ }^{4}$

\subsection{Hypotheses}

The experiment is designed to test the following hypotheses:

H1. Attraction: Arousing contents increase viewing time. Under this hypothesis, the viewing share for program $\mathrm{B}$ is expected to be higher in AC than in CC. Formally:

$$
H_{0}: V_{A C} \leq V_{C C} \text { vs } H_{1}: V_{A C}>V_{C C}
$$

where $V_{i}$ is viewing time for program $\mathrm{B}$, as a percentage of total viewing time, in condition $i$.

H2. Satisfaction with content: Arousing contents decrease satisfaction with program content. This hypothesis can take two forms:

H2a. Strong choice inconsistency: Arousing contents decrease satisfaction with program. Under this hypothesis, self-reported satisfaction with program $\mathrm{B}$ is expected to be lower in $\mathrm{AC}$ than in CC:

$$
H_{0}: S_{A C} \geq S_{C C} \text { vs } H_{1}: S_{A C}<S_{C C}
$$

where $S_{i}$ is satisfaction with content of program B in condition $i$ (as a percentage of total satisfaction for programs A,B and C).

H2b. Weak choice inconsistency: Arousing contents increase television consumption relatively more than satisfaction. Under this hypothesis, satisfaction with program $\mathrm{B}$, relative to viewing time, is expected to be lower in $\mathrm{AC}$ than in $\mathrm{CC}$ :

$$
H_{0}: R S_{A C} \geq R S_{C C} \text { vs } H_{1}: R S_{A C}<R S_{C C}
$$

where $R S_{i}=S_{i}-V_{i}$ is relative satisfaction with content of program $\mathrm{B}$ in condition $i$.

H3. Satisfaction, overall: Arousing contents decrease overall satisfaction with viewing. Under this hypothesis, self-reported satisfaction with overall viewing is lower in $\mathrm{AC}$ than in $\mathrm{CC}$ :

$$
H_{0}: O S_{A C} \geq O S_{C C} \text { vs } H_{1}: O S_{A C}<O S_{C C}
$$

where $O S_{i}$ is overall satisfaction with viewing in condition $i$.

\footnotetext{
${ }^{4}$ All the videos used in the experiment are available from the authors upon request.
} 


\subsection{Participants}

The experiment was conducted in the Experimental Economics Laboratory of the University of Milano-Bicocca between November and December 2010. Participants were undergraduate and graduate students from different backgrounds. We implemented 8 sessions, with 18 subjects per session. Since two sessions only had 16 subjects, we had 140 subjects in total. Two subjects were eliminated from the sample as they did not watch program $B$, and one because of a limited viewing time due to technical problems. The effective sample therefore includes 137 subjects (49 females). Average age is 22.9 $(\mathrm{SD}=1.9)$. Subjects were randomly assigned to the experimental and control conditions (66 and 71, respectively). Gender, in particular, is not related to the experimental condition (Pearson $\chi_{1}^{2}=0.32, \mathrm{p}<0.57$ ). Each subject was paid 10 euros for participating in sessions lasting about 25 minutes.

\subsection{Procedures}

The experiment was computerized, with terminals connected through a network controlled by the experimenter. Each subject was visually isolated from the other participants, so that all subjects had complete privacy with nobody being able to see their screen during the experiment. Subjects used headphones, so as to be completely isolated from other participants. The experiment was run with a double-blind procedure, so that subjects knew that their identity would not be known by other participants and by the experimenter.

In each session, subjects were randomly assigned to a computer terminal at their arrival. Instructions were presented on screen and read aloud. Questions were answered individually before the start of the viewing task. In each session, subjects went through two phases: the viewing task and a questionnaire on viewing satisfaction and background information (see the Appendix). Subjects were not informed at the beginning of the experiment that there would be a questionnaire after the viewing task, in order not to influence their viewing choices.

In the viewing task, a software interface simulating a TV set, written in Visual Basic, allowed subjects to simulate the task of watching television for 10 minutes, being able to choose among three programs. Choices were made in real time, so that subjects could switch at any time among the three programs. Both treatments were implemented in each session (half of the subjects were randomly assigned to AC and CC, respectively). The average duration of viewing spells was 38, 78 and 129 seconds for programs A, B, and $\mathrm{C}$, respectively. Average viewing time shares were $0.15,0.38$ and 0.47 for programs A, B, and C, respectively. At the end of the 10 minute viewing 
task, subjects were asked to fill in a questionnaire administered with the experimental software z-Tree (Fischbacher, 2007). Following related research on television satisfaction (Perse and Ferguson, 1993; Ferguson and Perse, 2004) we measured satisfaction using the questions "How satisfied are you with each of the three programs (on a scale between 1 and 10)?" and "Overall, how satisfied are you with the programs you have watched (on a scale between 1 and 10)?". The questionnaire also contained questions about a number of specific attributes for each program (see the Appendix).

\section{Results}

The experimental effects on all dependent variables were analyzed using a generalized linear model (GLM), with appropriate distributions and link functions (McCullagh, and Nelder, 1989). ${ }^{5}$ As an additional test of the robustness of the results, the effects of arousing contents on the experimental dependent variables were also tested using non-parametric Wilcoxon ranksum tests. The results of the non-parametric tests were qualitatively in line with the ones obtained with the GLM (Table 1).

For each dependent variable, a model with content ( $\mathrm{AC}$ vs $\mathrm{CC}$ ), type (Low vs High) and their interaction was estimated. As none of the analyses showed an interaction between the experimental factors (Table 2), we start by describing overall effects of content on viewing choices and satisfaction. Next, we examine the robustness of the results to the use of different program types. Finally, in order to interpret the experimental results, we investigate the self-reported assessment about program and overall viewing.

\subsection{The Effects of Arousing Content}

Figure 1 compares average viewing time and satisfaction levels across contents. In the presence of arousing contents, relative to the control condition, viewing time for program $B$ is higher, while both program-specific and overall viewing satisfaction are lower. This descriptive evidence is qualitatively consistent with the hypotheses.

\footnotetext{
${ }^{5}$ Generalized linear models were chosen in order estimate the effects of the two-bytwo experimental design for dependent variables with different distributional properties (McCullagh, and Nelder, 1989). Variables expressed as percentage were modelled with a logarithmic link function and a Tweedie distribution of errors (Jorgensen, 1987). All the other variables where modelled with a linear link function and a normal distribution of errors. Distributional assumptions and link functions were evaluated also in term of Akaike information criterion (AIC) (Lindsey, Jones, 1998). None of the experimental effects showed an interaction with gender, so this variable has been dropped from the analysis.
} 
Figure 1: Average viewing time and satisfaction, by content

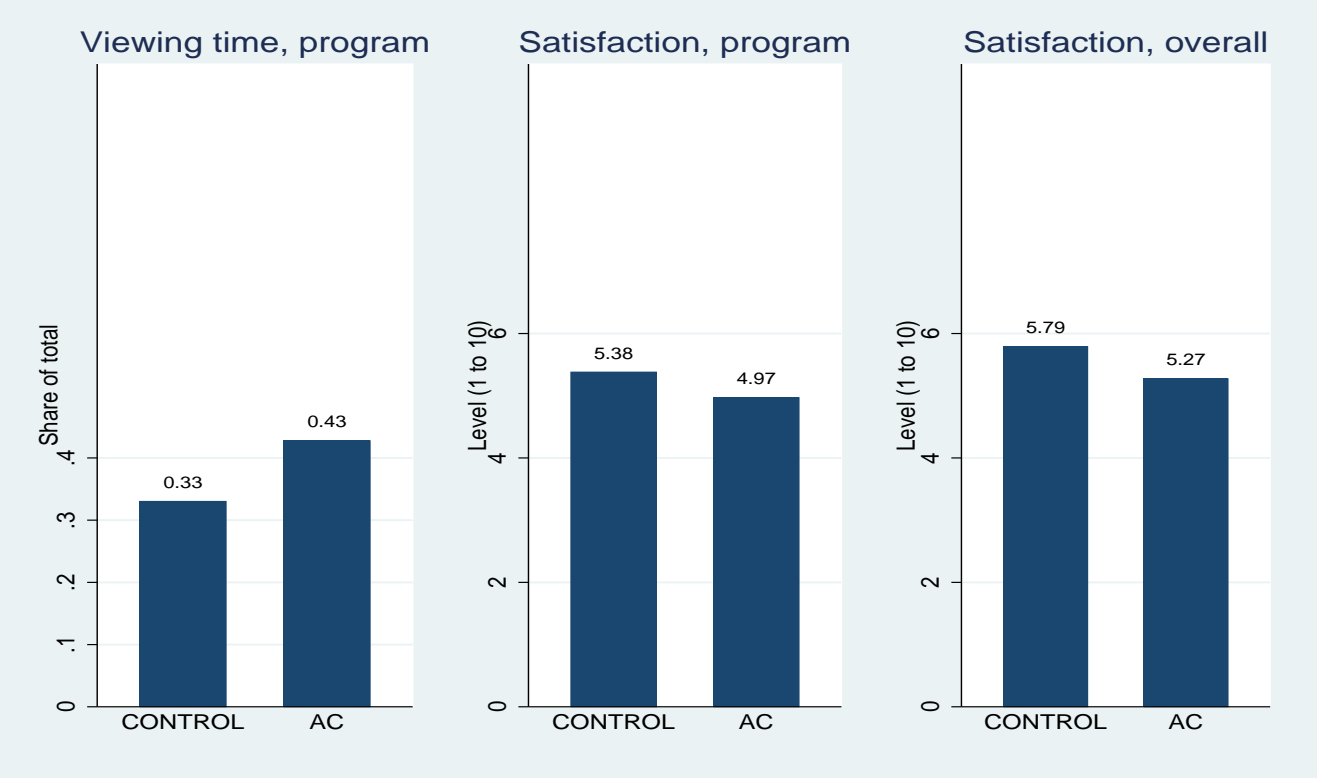

Table 1 reports average differences across content experimental conditions and significance levels for the corresponding hypotheses, based on GLM and Wilcoxon rank-sum tests. Viewing time for program B, as a share of total, is 42 per cent in the presence of arousing contents, as opposed to 33 per cent in the control condition. The difference is statistically significant $(p<0.021)$ and quantitatively relevant: viewing time for program $\mathrm{B}$ rises by about a third in the presence of arousing contents.

Table 1: Effects of arousing content on consumption and satisfaction

\begin{tabular}{lccccc}
\hline Variable & CC & AC & Difference & GLM p. & RS p. \\
\hline Viewing time & 0.33 & 0.43 & 0.10 & 0.021 & 0.046 \\
Excess viewing & -0.03 & 0.05 & 0.08 & 0.002 & 0.022 \\
Satisfaction, program & 5.38 & 4.97 & -0.41 & 0.179 & 0.201 \\
Relative satisfaction, program & 0.02 & -0.09 & -0.11 & 0.005 & 0.012 \\
Satisfaction, overall & 5.27 & 5.79 & -0.52 & 0.036 & 0.039 \\
\hline
\end{tabular}

Note: all p-values are one-tailed. GLM=Generalized linear model, RS=Wilcoxon Ranksum test.

Result 1: Arousing contents significantly increase viewing time.

Is this increase in viewing consistent with individual preferences? One way to answer this question is to compare actual viewing time (hot choice) 
with desired viewing time (cold choice) ${ }^{6}$ Desired viewing time is virtually unchanged across experimental conditions ( 0.36 and 0.38 in $\mathrm{CC}$ and $\mathrm{AC}$, respectively, $\mathrm{p}<0.40$ ). As a result, excess consumption, defined as the difference between actual and desired viewing time, is significantly higher in the experimental condition $(0.08, \mathrm{p}<0.002)$.

Result 2: Arousing contents significantly increase excess consumption.

These results for excess viewing indicate that actual viewing choices are not always consistent with preferences and, in particular, are systematically biased in the presence of arousing contents. We now turn to self-reported satisfaction with program content to assess more directly the hypothesis of choice inconsistency. Satisfaction with program B, on a scale between 1 and 10, is 4.97 in $\mathrm{AC}$, as opposed to 5.38 in CC (Table 1). The difference, however, is not statistically significant $(\mathrm{p}<0.18)$. The hypothesis of strong choice inconsistency is not supported by the evidence.

Result 3: Arousing contents decrease satisfaction with program but the difference is not significant.

In order to test the hypothesis of weak choice inconsistency, we construct a measure of relative satisfaction, defined as the difference between satisfaction with program and viewing time, both defined as a share of the total for the three programs. Relative satisfaction is lower in the experimental condition $(-0.11)$, and the difference is strongly statistically significant $(p<0.005)$.

Result 4: Arousing contents significantly decrease relative satisfaction with program.

Finally, we turn to the global assessment of the viewing experience. Overall satisfaction, defined on a scale between 1 and 10, is 5.27 in AC, as opposed to 5.79 in $\mathrm{CC}$, and the difference is statistically significant $(\mathrm{p}<0.036)$. The hypothesis of overall inconsistency is supported by the experimental data.

Result 5: Arousing contents have a significant negative effect on overall viewing satisfaction.

\footnotetext{
${ }^{6}$ This variable is constructed on the basis of the question "If at the end of the questionnaire you were to watch the three programs for 10 additional minutes, what percentage of total time would you want to spend on each program?".
} 


\subsection{Generalization across Program Types}

In order to assess the robustness of the effects of arousing contents to the use of alternative program target audience, the experimental manipulation on program B was performed using two different talk shows. The first, with a relatively lowbrow target audience, focuses on real-life stories. The second, with a relatively highbrow target audience, focuses on current political issues. The difference of the two targets is clearly reflected in subjects' choices. The average share of viewing time is 0.23 and 0.52 for the lowbrow and highbrow targets, respectively, and the difference is strongly significant $(p<0.001)$. Satisfaction with program content and with overall viewing are also significantly higher for the highbrow version $(\mathrm{p}<0.001)$. Figure 2 compares average viewing time and satisfaction levels, by content, across program target audience.

Figure 2: Viewing and satisfaction, by treatment and program type

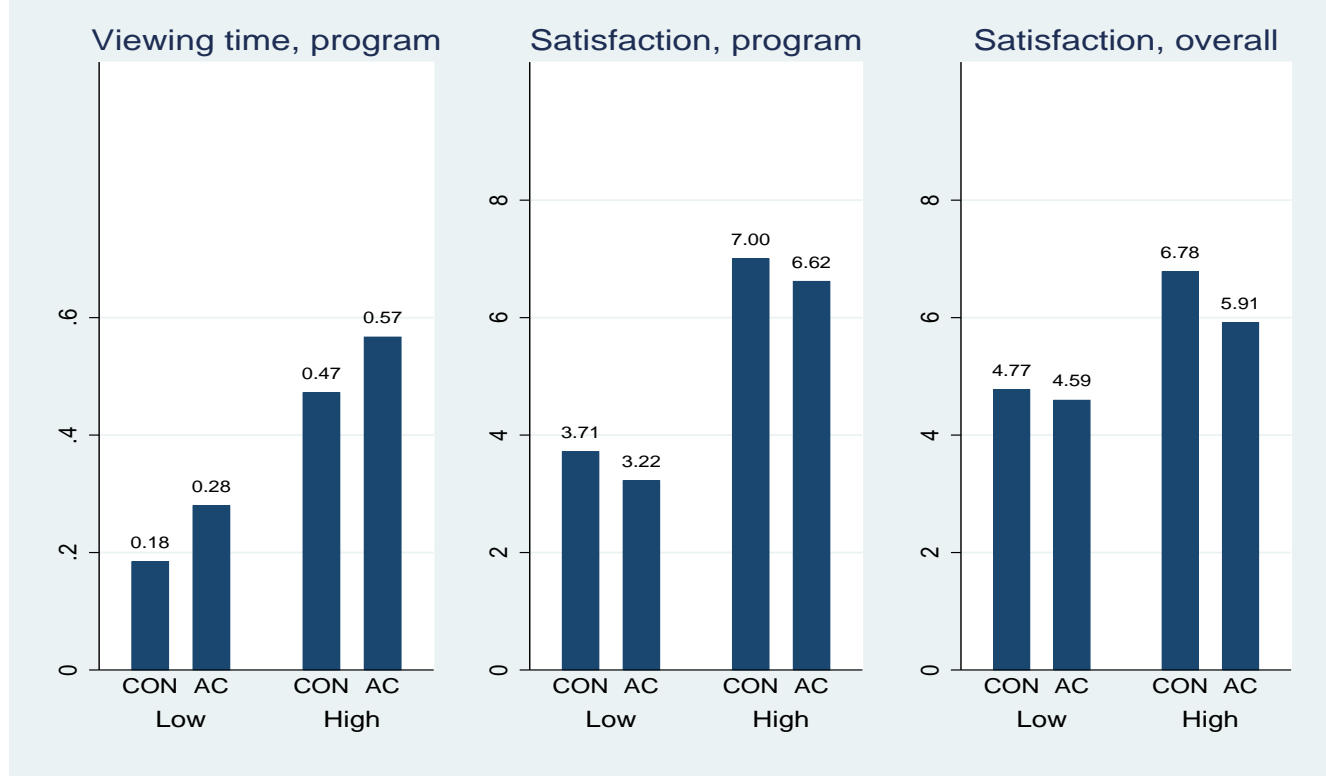

Importantly, the effect of arousing contents on viewing time is very similar across the two versions of the talk show (0.10 and 0.09 in Low and High, respectively). The effect of arousing contents on satisfaction with program content is negative for both low and high target audience. Relative satisfaction with program content (with respect to viewing time) and the effect on overall satisfaction are also consistent in the two target audience conditions. The consistency is supported by the lack of interaction effects between program content and type for all the variables of interest (Table 2).

Result 6: There is no significant interaction between arousing content and program type. 
Table 2: Effect of program target audience and interaction with content

\begin{tabular}{lcccc}
\hline \multirow{2}{*}{ Variable } & \multicolumn{2}{c}{ Program Type } & \multicolumn{2}{c}{ Interaction } \\
& $\chi^{2}$ & p. & $\chi^{2}$ & p. \\
\hline Viewing time & 29.25 & 0.001 & 0.59 & 0.449 \\
Excess viewing & 3.59 & 0.058 & 1.19 & 0.274 \\
Satisfaction with program & 54.20 & 0.001 & 0.98 & 0.321 \\
Relative satisfaction with program & 5.86 & 0.015 & 0.199 & 0.655 \\
Satisfaction, overall & 32.60 & 0.001 & 1.39 & 0.237 \\
\hline
\end{tabular}

Note: For each dependent variable, experimental effects of content, target, and their interaction were estimated with a generalized linear model. All p-values are two-tailed.

Overall, these results indicate that the effects of arousing contents are robust to the use of alternative program targets. More specifically, the inconsistencies between actual and desired viewing time, and between viewing and content-specific satisfaction are stronger when arousing contents are present in relatively lowbrow programs. On the other hand, the inconsistency between viewing decisions and overall satisfaction is stronger when arousing contents are present in relatively highbrow programs.

\subsection{Viewing Perception}

The evidence reported so far indicates that, in the presence of arousing contents, subjects watch more of a given program, against their own will and interest. Why do they do it? We address this question by examining information about the perception of viewing as reported in the post-experimental questionnaire. Figure 3 compares program-specific and overall perceptions about viewing across contents.

The first question we ask is: Are subjects aware of their viewing choices? That is, do they have a correct perception of the time spent on each program? The answer is positive. When asked to estimate ex-post the share of viewing time for program B, subjects report on average 0.36 and 0.43 per cent for the control and experimental conditions, respectively. These figures are remarkably close to actual viewing time, indicating that subjects are well aware of the viewing choices they made. In addition, the difference in perceived viewing time between treatments is statistically significant, although only marginally $(p<0.10)$. Second, How do subjects rate the quality of program B across treatments? The perceived quality of program B falls from 5.75 in the control condition to 4.88 in the experimental condition, and the difference is strongly significant $(\mathrm{p}<0.03)$. This indicates that subjects are aware that they are watching more of a program they consider of lower quality. Next, consider the perception of the viewing experience as a whole. When asked to rate the attractiveness and quality of viewing overall, subjects 
Figure 3: Perception of viewing, by treatment
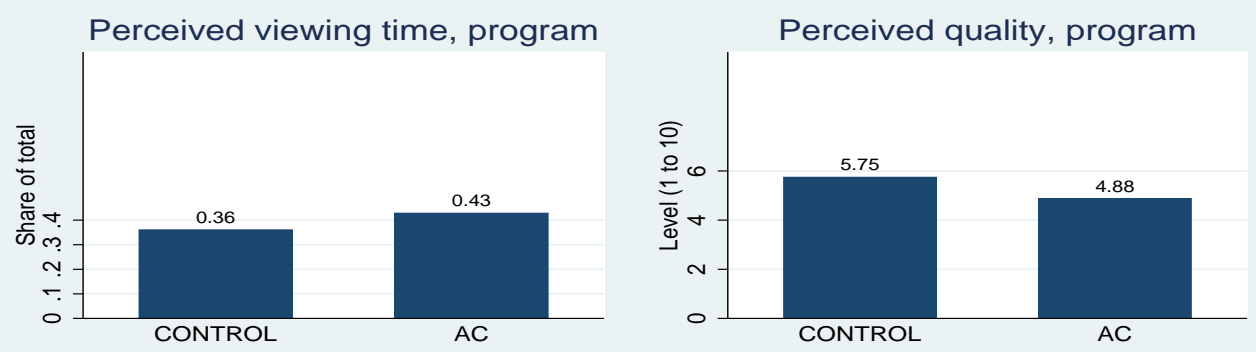

Perceived attractiveness, overall

Perceived quality, overall
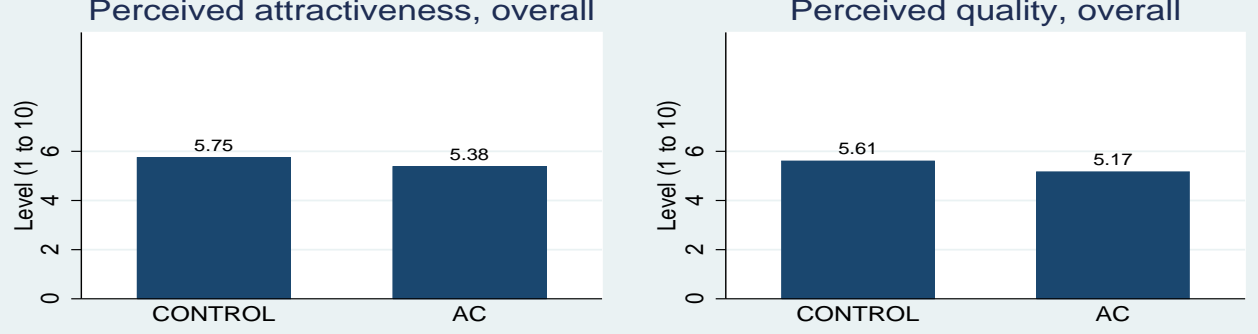

report substantially lower values in the experimental condition $(\mathrm{p}<0.08$ and $\mathrm{p}<0.06$ for attractiveness and quality, respectively).

Result 7: The effects of arousing content on viewing and satis-

faction are clearly perceived by the subjects.

Table 3 reports differences across treatments of self-reported assessments of individual characteristics of program B. In the presence of arousing contents, program $B$ is perceived as significantly more violent and vulgar $(p<0.00$ for both variables). It is also perceived as less instructive $(\mathrm{p}<0.07)$, less relaxing $(\mathrm{p}<0.07)$ and less suitable to a general public $(\mathrm{p}<0.01)$. Interestingly, program B is reported to be significantly more funny $(\mathrm{p}<0.02)$ : this is the only positive feature that can be related to the increase in viewing time across treatments. Overall, subjects clearly perceive several negative features of arousing content. Nevertheless, as in Postman (1986), they appear to be amusing themselves to death.

\section{Conclusions}

Our experimental results indicate that, in a situation of free choice between different TV programs, the presence of arousing contents causes subjects to watch more of a given program, although they experience lower contentspecific and overall satisfaction. Arousing content also significantly increases 
Table 3: Assessment of program contents, by treatment

\begin{tabular}{lcccc}
\hline \hline & Control & $\mathrm{AC}$ & Difference & $\mathrm{p}$-value \\
\hline Funny & 3.55 & 4.52 & 0.97 & 0.02 \\
Involving & 5.38 & 5.26 & -0.12 & 0.38 \\
Instructive & 5.46 & 4.71 & -0.75 & 0.07 \\
Relaxing & 3.87 & 3.35 & -0.52 & 0.07 \\
Original & 3.63 & 3.65 & 0.02 & 0.50 \\
Well Done & 4.99 & 4.39 & -0.59 & 0.09 \\
Suitable to all & 4.75 & 3.83 & -0.91 & 0.01 \\
Vulgar & 3.76 & 6.18 & 2.42 & 0.00 \\
Violent & 2.41 & 4.77 & 2.36 & 0.00 \\
Useful & 5.62 & 5.09 & -0.53 & 0.18 \\
\hline
\end{tabular}

Note: For each variable, the significance of treatment effects is evaluated with Wilcoxon rank-sum tests. All the p-values are two-tailed.

excess consumption, defined as the difference between actual and desired viewing. Several issues need to be considered in order to interpret these findings.

First, consider the role that can be played by social desirability. It is possible that the lower levels of satisfaction reported in the presence of arousing content reflect the tendency of respondents to reply in a manner that will be viewed favorably by others. In our analysis, we tried to overcome social desirability bias in two ways: first, we implemented a completely anonymous protocol for data collection; second, we measured satisfaction not only in relation to a specific content but also with respect to the overall viewing experience. It is important to note that the presence of arousing content produces a significant fall in the overall satisfaction with viewing. As social desirability mainly applies to the social image of specific programs, this result cannot be explained by social desirability, given that benchmark programs are kept constant across treatments.

Second, the external validity. As our sample is composed of university students, and there is limited variability in variables such as age and education, it is difficult to assess if the effects of arousing content on viewing and satisfaction extend to the whole population and how they are affected by socio-demographic characteristics. In our experimental analysis we find no significant interaction between arousing content and gender. Nevertheless, it would be interesting to replicate the experiment with different target audience types.

Third, following past research on television satisfaction (Perse and Ferguson, 1993; Ferguson and Perse, 2004) we have measured satisfaction by asking subjects about their satisfaction with individual programs and overall 
viewing. However, the concept of satisfaction is a complex one. Communication scholars have focused on media appreciation, entertainment, and other related concepts, such as for example "enjoyment" (Green et al. 2004). We need a better understanding of what exactly subjects evaluate when they answer these questions.

Some additional issues remain open for future research. In particular, the question: Why exactly does verbal violence, or more generally arousing content, produce a lower satisfaction with viewing? One possibility is that viewers are attracted by arousing content irrespective of their appreciation, so that their consumption choices end up being sub-optimal. In this perspective, the lower level of satisfaction would derive from a phenomenon of "distraction". Another explanation is that the mere exposure to verbal violence can determine dissatisfaction per se. In this perspective, dissatisfaction would be the effect of the content itself.

The present study poses several challenges to both social theory and media regulation policies. Within a framework of rational choice, viewers should always be able to choose for their best. In media studies, this view is expressed by the theory of uses and gratifications (Blumler and Katz, 1974). The basic idea of this theory is that people use the media to obtain specific gratifications. Therefore, a medium will be used more when the existing motives to use it lead to more satisfaction. Similarly, in economics, if people choose to watch specific contents on TV, this must be in their own interest. While the theory of revealed preferences has been challenged by research in many areas of consumption, we argue that television consumption provides a major example of consumption choices that may not maximize utility. This may reflect a number of specific reasons. First, in decisions about commercial TV viewing, the product is virtually free, as it is paid for by advertising. Even in cable TV or satellite TV, the costs of the single exposure are marginal. This makes TV consumption a low-cost activity in which impulse choices are much more frequent than pre-determined choices. Second, TV viewing represents a leisure activity with the goal of producing immediate relaxation with low involvement. This makes the users keep activation costs at their lowest level. As a consequence, people may find it difficult to choose contents they can be satisfied with when arousing contents are portrayed. As a result, inconsistent choices are much more likely to occur.

This mechanism can explain biases in the individual decision making process during TV watching. However, it also opens the question of the existence of a widespread overconsumption of arousing media stimuli at a societal level. In this paper, we focused more on the first issue. Further research will analyze the long-run and social consequences of this phenomenon. Finally, the corroboration of the results presented in this study could challenge the use 
of audience figures as a measure of appreciation or audience satisfaction, as it is common in the media market. In fact, if specific contents produce a systematic gap between consumption and satisfaction, we would be facing a failure of the media market. In terms of system balance and functionality, appropriate regulation policies might be needed to tackle this phenomenon. 


\section{Appendix: Post-experimental questionnaire}

- Overall, how satisfied are you with the programs you have watched (on a scale between 1 and 10)?

- What is your overall assessment of the quality of the programs you have watched (on a scale between 1 and 10)?

- What is your overall assessment of the ability of the programs you have watched to keep you involved (on a scale between 1 and 10)?

- Which of the three programs did you like the most?

- How satisfied are you, on a scale between 1 and 10, with each of the three programs?

- Program A 12345678910

- Program B 12345678910

- Program C 12345678910

- What is your assessment of the quality of each of the programs you have watched (on a scale between 1 and 10)?

- Program A 12345678910

- Program B 12345678910

- Program C 12345678910

- If you should watch for 10 more minutes only one of the three programs, which of them would you choose?

- If you should watch for 10 more minutes one or more of the three programs, what percentage of these 10 minutes would you dedicate to each of them?

- During the experiment, what percentage of total time do you think you have allocated to each of the programs?

- Had you already seen, before today, any of the three programs used in the experiment?

Program A Y N

Program B Y N

Program C Y N 
- Had you already seen, before today, any of the three specific episodes used in the experiment?

$\begin{array}{lcc}\text { Program A } & \text { Y } & \text { N } \\ \text { Program B } & \text { Y } & \text { N } \\ \text { Program C } & \text { Y } & \text { N }\end{array}$

- With respect to each of the three programs, how much do you agree with the following statements (on a scale between 1 and 10):

- It is fun

- It is involving

- It is instructive

- It is relaxing

- It is original

- It is well done

- It is suitable to everyone

- It is vulgar

- It is useful 


\section{References}

Anderson, C. A., Bushman, B.J., 2001. Effects of violent video games on aggressive behavior, aggressive cognition, aggressive affect, physiological arousal, and prosocial behavior: a meta-analytic review of the scientific literature. Psychol. Sci., 12 (5), 353-359

Ang I., 1985. Watching Dallas: Soap Opera and the Melodramatic Imagination, Methuen, New York.

Baruh L., 2009. Publicized Intimacies on Reality Television: An Analysis of Voyeuristic Content and Its Contribution to the Appeal of Reality Programming, Journal of Broadcasting \& Electronic Media, 53 , 2. 190-210.

Benesch, C., Frey, B., Stutzer, A., 2006. TV Channels, Self Control and Happiness. IEW Working Paper No. 301, University of Zurich.

Blumler J., Katz E., 1974. The Uses of Mass Communication. Thousand Oaks, CA: Sage.

Bolls, P., Potter, R., Lang, A., 1996. Television arousal and memory: the effects of production pacing and arousing content on encoding, storage, and retrieval of television messages. In M. Gasser, Online proceedings of the 1996 Midwest Artificial Intelligence and Cognitive Science Conference

Bourdieu, P., 1998. On television. New York: The New Press.

Bruni, L., Stanca, L., 2006, Income Aspirations, Television and Happiness: Evidence from the World Values Survey, Kyklos, 59(2), 209-225.

Bruni, L., Stanca, L., 2008, Watching alone: Relational Goods, Television and Happiness, Journal of Economic Behavior and Organization, 65(34), 506-528.

Chibnall S., 1977. Law and order news: An analysis of crime reporting in the British press, London: Tavistock Publications.

Cutler D. M., Glaeser E. L., Shapiro J.M., 2003. Why Have Americans Become More Obese?, Journal of Economic Perspectives, 17(3), pp. 93-118.

Ferguson, D., Perse, E., 2004. Audience Satisfaction among TiVo and Replay Users, Journal of Interactive Advertising, 4 (2). 
Fischbacher, U., 2007. z-Tree: Zurich toolbox for ready-made economic experiments, Experimental Economics, 10(2), 171-178.

Frey B., Benesch C., Stutzer A., 2007. Does Watching TV Make Us Happy?, Journal of Economic Psychology, 28(3. pp. 283-313.

Gerbner, G., Gross, L., Morgan, M., Signorielli, N., Jackson-Beeck, M., 1979. The demonstration of Power: Violence Profile No. 10. Journal of Communication, 29, 177-196.

Gerbner, G., Gross, L., Morgan, M., Signorielli, N., 1980. The "mainstreaming" of America: Violence profile no. 11. Journal of Communications, 30, 10-29.

Grabe, M. E., Lang, A., Zhao, X., 2003. News content and form. Communication Research, 30, 387-414

Grabe, M. E., Zhou, S., Barnett, B., 2001. Explicating sensationalism in television news: Content and the bells and whistles of form. Journal of Broadcasting \& Electronic Media, 45(4), 635-655.

Green M., Brock T., Kaufman G., 2004. Understanding Media Enjoyment: The Role of Transportation Into Narrative Worlds, Communication Theory, Volume 14, Issue 4,

Grimm, J., 1996. Between Anxiety and Aggression, Physiological and Psychological Effects of Television Violence', paper for the Eighth Congress of the Association of Europe Psychiatrists, section Psychiatry and Media, London.

Gruber J., Mullainathan S., 2002. Do Cigarette Taxes Make Smokers Happier?, NBER Working Paper No. 872, Cambridge, MA: National Bureau of Economic Research

Gui, M., Stanca, L., 2009. Television Viewing, Satisfaction and Happiness: Facts and Fiction, Working Paper No. 167, University of MilanoBicocca, Department of Economics.

Gul, F., Pesendorfer, W., 2005. The Case for Mindless Economics. Levine's Working Paper Archive, 2005-11-13.

Gunter B., Wober M., 1992. The Reactive Viewer. London: John Libbey and Company. 
Hardy, A., De Swert, K., Sadicaris, D., 2010. Does Market-Driven Journalism Lead to Sensationalism in Television News? Explaining Sensationalism in 11 Countries, Paper presented at the annual meeting of the International Communication Association, Suntec Singapore International Convention \& Exhibition Centre, Suntec City, Singapore Online.

Hendrik Vettehen, P., Nuijten, M., Beentjes, J.W., 2005. News in an age of competition: Sensationalism in Dutch television news 1995-2001. Journal of Broadcasting \& Electronic Media, 49, 282-295.

Hendrik Vettehen, P., Nuijten, K., Peeters, A.. 2008. Explaining effects of sensationalism on liking of television news stories: the role of emotional arousal. Communication Research, 35(3), 319-338.

Heuvelman A., Peeters A., van Dijk J., 2005. Irritating, shocking, and intolerable TV programs: Norms, values, and concerns of viewers in The Netherlands, Communications. Volume 30(3), 325-342.

Hoch S., Loewenstein, G., 1991. Time-Inconsistent Preferences and Consumer Self-Control, Journal of Consumer Research, University of Chicago Press.

Johnson, J.G., Cohen, P., Smailes, E.M., Kasen, S., Brook, J.S., 2002. Television viewing and aggressive behavior during adolescence and adulthood. Science, 295, 2468-2471.

Jorgensen, B., 1987. Exponential dispersion models. Journal of the Royal Statistical Society B, 49, 127-162.

Ishikawa S. (Ed.)., 1996. Quality assessment of television. Luton, UK: John Libbey Media.

Krcmar, M., Greene, K., 1999. Predicting exposure to and uses of television violence. Journal of Communication, 49(3), 24-45.

Kubey, R., Csikszentmihalyi, M., 1990. Television and the quality of life: How viewing structures everyday experience. Hillsdale, NJ: Lawrence Erlbaum.

Lacey, B. C., Lacey, J., 1974. Studies of heart reate and other bodily processes sensorimotor behavior. In P. A. Obrist, A. H. Black, J. Brenner, \& L. V. DiCara (Eds.), Cardiovascular psychophysiology: Current issues in response mechanisms, biofeedback, and methodology (pp. 538568). Chicago: Aldine. 
Lang, A., 1990. Involuntary attention and physiological arousal evoked by structural features and emotional content in TV commercials. Communication Research, 17, 275-299.

Lang, A., 1994. What can the heart tell us about thinking In A. Lang (Ed.), Measuring psychological responses to media messages. Hillsdale, NJ: Erlbaum.

Lang, A., Dhillon, K., Dong, Q., 1995. The effects of emotional arousal and valence on television viewers' cognitive capacity and memory. Journal of Broadcasting \& Electronic Media, 39(3), 313-327.

Lang, A., Newhagen, J., Reeves, B., 1996. Negative Video as Structure: Emotion, Attention, Capacity, and Memory. Journal of Broadcasting \& Electronic Media, 40, 460-477.

Lang, A., Potter, D., Grabe, M.E., 2003. Making News Memorable: Applying Theory to the Production of local Television News, Journal of Broadcasting \& Electronic Media, 47:1, 113-123.

Lang, A., Bolls, P., Potter, R., Kawahara, K., 1999. The Effects of Production Pacing and Arousing Content on the Information Processing of Television Messages, Journal of Broadcasting \& Electronic Media, 43 (4), 451-475.

Lang, A., Park, B., Sanders-Jackson, A. N., Wilson, B. D., Zheng, W., 2007. Cognition and emotion in TV message processing: How valence, arousing content, structural complexity, and information density affect the availability of cognitive resources. Media Psychology, 10(3), 317338

Leggatt T., 1996. Identifying the undefinable: An essay on approaches to assessing quality in television in the UK, in S. Ishikawa (Ed.). Quality assessment of television, John Libbey Media Luton, UK.

Lindsey, J.K., Jones, B., 1998. Choosing among generalized linear models applied to medical data. Statistics in Medicine, 17(1), 59-68.

Lundy L., Ruth A, Park T., 2008. Simply Irresistible: Reality TV Consumption Patterns, Communication Quarterly, Volume 56, Issue 2 April 2008 , pages $208-225$

Meijer I. C., 2007. The paradox of popularity: How young people experience the news, Journalism Studies, vol. 8, no. 1, pp. 96-116. 
Meyers, M., 1997. News coverage of violence against women: Engendering blame. Thousand Oaks, CA: Sage.

McQuail D., 1997. Audience analysis, Sage, London.

McQuail D., 2005. McQuail's Mass Communication Theory, Sage.

Morrison D., 1986. Invisible citizens: British public opinion and the future of broadcasting, Broadcasting Research Unit, John Libbey, London.

Newhagen, J.E., 1998. TV News Images that Induce Anger, Fear and Disgust: Effects on Approach-Avoidance and Memory, Journal of Broadcasting \& Electronic Media 42(3), 265-76.

Newhagen, J.E., Reeves, B., 1992. The evening's bad news: Effects of compelling negative television news images on memory. Journal of Communication, 42(2), 25-42.

Perse E.M., Ferguson D.A., 1993. The Impact of Newer Television Technologies on Television Satisfaction, Journalism Quarterly, 70, 843-853.

Popper, K., 1993. Against television. BBC interview on April 13, 1993.

Postman, N., 1986. Amusing Ourselves to Death: Public Discourse in the Age of Show Business, Penguin Books.

Potter, J., 1996. Representing Reality: Discourse, Rhetoric and Social Construction. London: Sage Publications.

Samuelson L., Swinkel J., 2006. Information, evolution and utility, Theoretical Economics, 1.

Shanahan, J., Morgan, M., 1999. Television and its viewers: Cultivation theory and research. Cambridge: Cambridge University Press

Shapiro, J.M., 2005. Is there a daily discount rate? Evidence from the food stamp nutrition cycle. Journal of Public Economics, 89(2-3), 303-325.

Simons R.F., Detenber, B.H., Cuthbert, B.N., Schwartz, D., Reiss, J.E., 2003. Attention to Television: Alpha Power and Its Relationship to Image Motion and Emotional Content, Media Psychology, Volume 5, Issue $3,283-301$

Slattery, K.L., Doremus, M., Marcus, L., 2001. Shifts in public affairs reporting on the network evening news: A move toward the sensational. Journal of Broadcasting \& Electronic Media, 45, 290-302. 
Weimann G., Brosius H.B., Wober M., 1992. TV diets: Toward a typology of TV viewership, European Journal of Communication, 7, pp. 491515 .

Weaver A.J., Wilson B.J., 2009. The Role of Graphic and Sanitized Violence in the enjoyment of Television Dramas Human Communication Research 35, 442-463.

Van der Molen, W., Valkenburg, P.M., Peeters, A.L., 2002. Television News and Fear: A Child Survey, Communications: European Journal of Communication Research 27: 303-17.

Uribe, R., Gunter, B., 2007. Are 'Sensational' News Stories More Likely to Trigger Viewers' Emotions than Non-Sensational News Stories? : A Content Analysis of British TV News, European Journal of Communication, 22: 207.

Walker, J., Bellamy, R., 1993. The remote control device in the new age of television, New York: Praeger.

Wober J.M., 1990. The assessment of television quality: Some explorations of methods and their results, IBA Research Department, London.

Wood, H., 2001. No YOU Rioted!: The Pursuit of Conflict in the Management of "Lay" and "Expert" Discourses in Kilroy", in A. Tolson (ed.) Television Talk Shows: Discourse, Performance, Spectacle, pp. 65-88. Mahwah, NJ: Lawrence Erlbaum Associates. 